\title{
Correction to: Orgasm Equality: Scientific Findings and Societal Implications
}

\author{
Elizabeth A. Mahar ${ }^{1} \cdot$ Laurie B. Mintz $^{1} \cdot$ Brianna M. Akers ${ }^{1}$
}

Published online: 22 January 2020

(C) Springer Science+Business Media, LLC, part of Springer Nature 2020

\section{Correction to: Current Sexual Health Reports} https://doi.org/10.1007/s11930-020-00237-9

The original article unfortunately contained mistakes. In the table, "95\% usually always orgasm ${ }^{2 "}$ was not changed to "95\% usually-always orgasm ${ }^{\mathrm{b}}$ ".

The original version has been corrected.

The online version of the original article can be found at https://doi.org/ 10.1007/s11930-020-00237-9

\footnotetext{
Laurie B. Mintz

mintzl@ufl.edu

Elizabeth A. Mahar

emahar@ufl.edu

Brianna M. Akers

briannamakers@ufl.edu

1 Department of Psychology, University of Florida, P.O. Box 112250, Gainesville, FL 32611-2250, USA
} 